\title{
Dilemas y rupturas entre yachak y la figura del poncho dorado en Ecuador*
}

\author{
GEMA TABARES MERINO**
}

\begin{abstract}
Dilemmas and Ruptures Between YachaK and the Figure of THE Golden Poncho In ECUADOR. This article analyzes the creation of an internal elite in indigenous peoples and nationalities of contemporary Ecuador. Social advancement of indigenous intellectuals is considered in order to determine how the accumulation of a certain amount of capital allows individuals to advance into other social fields, such as the political and academic, and their role face to the Citizens' Revolution. Therefore, the approach to the problem focuses on circumscribing the legitimacy of the analytical category of the indigenous elite.
\end{abstract}

Key words: indigenous movement, plurinational State, indigenous elites, Citizens' Revolution

\begin{abstract}
Resumen
Este artículo busca analizar la construcción de una élite interna en los pueblos y nacionalidades indígenas del Ecuador contemporáneo, es decir, se estudia el ascenso social de los intelectuales indígenas para conocer cómo la acumulación de un determinado capital permite movilizar a los agentes en otros campos sociales, como el político y el académico, y cómo se posicionan frente a la Revolución Ciudadana. Por tanto, el planteamiento del problema se centra en delimitar la legitimidad de la categoría analítica de élite indígena.
\end{abstract}

Palabras clave: movimiento indígena, Estado plurinacional, élites indígenas, Revolución Ciudadana

\section{Introducción}

$\mathrm{E}$ n este artículo $^{1}$ se analiza la construcción de una élite interna en los pueblos y nacionalidades indígenas del Ecuador contemporáneo, determinada por una serie de factores históricos, con el propósito de examinar en qué medida la existencia de esta élite indígena plantea una contradicción para la lucha histórica de los pueblos y nacionalidades o viceversa, en qué medida contribuyen estos agentes al proyecto político de la refundación del Estado y cuál es su campo de acción en la Revolución Ciudadana.

Las preguntas guía para el análisis fueron las siguientes: ¿cuáles son los tipos de élites indígenas, dependiendo de los capitales movilizados y los campos sociales ocupados?, ¿cuál ha sido el aporte de las élites indígenas en la construcción del Estado plurinacional?, ¿cuál es el rol de éstas en el actual estado de crisis del movimiento indígena?

Durante el trabajo de campo realizado en Ecuador, llamaba mi atención el hecho de que, cuando conversé con los agentes acerca de las élites indígenas, directamente recurrían a la figura discursiva de poncho dorado,

\footnotetext{
* Artículo recibido el 26/04/17 y aceptado el 03/10/17.

** Revisora de la Revista Latinoamericana de Comunicación CHASQUI, del Centro Internacional de Estudios Superiores de Comunicación para América Latina (CIESPAL) <tabaresmerino@gmail.com>.

${ }^{1}$ Este artículo sintetiza los hallazgos centrales de mi investigación doctoral (2016) titulada "Estratificación de clases y crisis en el movimiento indígena del Ecuador: élites indígenas. El síndrome del "poncho dorado”.
} 
y con frecuencia señalaban: "allí tienes a los ponchos dorados, Tibán, Kowii, Tituaña”, ${ }^{2}$ por tanto, me cuestioné por qué estos agentes representaban esa figura discursiva (figura que se irá explicando a lo largo de este trabajo). Entonces, decidí usar tal expresión para conocer qué implicaba; en efecto, era obligatorio buscar su fabricación discursiva, y, ante ello, surgían nuevas preguntas de análisis: ¿cómo operaba la legitimidad de la figura de poncho dorado en el discurso de los intelectuales?, ¿por qué resultaba una figura (a veces) censurada entre los agentes indígenas?, ¿quién sí y quién no podría recurrir a esta construcción discursiva?, ¿cuáles son los dilemas y las rupturas entre los yachak ${ }^{3}$ y los parámetros occidentales de la figura discursiva de poncho dorado? Sin duda, las representaciones respondían a una apreciación social y cultural; así, las temáticas alrededor de la actividad social del agente indígena se volvían más discutibles para la investigación.

En este artículo explicaré de dónde surgió mi interés por el estudio de las élites indígenas en Ecuador, por qué coloco en debate la figura discursiva de poncho dorado y cómo la utilizo. Enseguida, describo un breve contexto político ecuatoriano. Después, presento una propuesta (construida mediante datos etnográficos) de por qué considero conveniente hablar de estratificación social en el mundo indígena. De entrada, sostengo que la búsqueda y propuesta de una nueva perspectiva teórica, otorgada por el estudio de las élites indígenas, contribuye a la necesaria superación del reduccionismo economicista que caracteriza al marxismo ortodoxo, al identificar de manera exclusiva a dichos grupos dominantes con la propiedad de los medios de producción. Finalmente, expongo unas conclusiones acerca de las disyuntivas entre los yachak y los parámetros occidentales de la figura discursiva de poncho dorado.

La investigación se inscribe dentro de la perspectiva de una antropología total, ${ }^{4}$ planteada por Pierre Bourdieu, pues metodológicamente encuentra su interés en los agentes ubicados en el campo políticoacadémico, y en la lucha política por la empresa de una nueva relación entre el Estado plurinacional y los pueblos y nacionalidades indígenas del Ecuador. Más que una etnografía tradicional, privilegio una etnografía del yuyanacuna (pensar entre dos), que permite comprender y mirar desde otros ángulos la estratifi- cación de clase y el debilitamiento político del movimiento indígena. Esta trascendental propuesta es señalada por los intelectuales indígenas con el objetivo de no perder de vista los marcos filosóficos en la construcción de un conocimiento, desde prácticas diversas de aprendizaje.

\section{Sobre el estudio de la élite indígena en Ecuador}

La búsqueda de maneras críticas y, sobre todo, actuales para pensar el ejercicio de los intelectuales indígenas en la construcción del Estado plurinacional motivó la presente investigación. La inspiración brotó simplemente de una coyuntura política. El evento fue que el presidente Rafael Correa nombró a Ricardo Ulcuango, dirigente histórico del movimiento indígena, embajador de Ecuador en Bolivia. Escuchaba entre "pasillos académicos" lo "triste" y el "dolor" que causaba este suceso político. Entre reuniones académicas se decía: "es nefasto, terrible, nos da vergüenza colectiva porque la repercusión de los indígenas es colectiva y de hecho, lo que ha perdido [Ulcuango] es legitimidad, respeto, y respeto no como persona, sino en relación a su discurso, a su coherencia, a su palabra”. Así, me enteré que "arrancaban" del movimiento a uno de los dirigentes más importantes de la lucha histórica de los pueblos y nacionalidades.

En primer lugar, este ejemplo me llevó a cuestionar las prebendas institucionales y la cooptación política por parte del gobierno de la Revolución Ciudadana. Estas prácticas tenían poco que ver con mi forma convencional de percibir el surgimiento de los llamados "países progresistas", por lo tanto, me permitió deconstruir los prejuicios sedimentados en mis "maneras académicas" de entender al gobierno encabezado por Correa.

En segundo lugar, no pretendí enjuiciar el hecho de que los agentes indígenas participen en la política instituida moderna, pues sabía que en esto radicaba la propuesta política de la Confederación de Nacionalidades Indígenas del Ecuador (Conaie) de "estar incluidos" e "incidir en las agendas públicas" desde el Estado. Esto último me entusiasmaba, y quería adentrarme a examinar cómo operaba el agente indígena en la arena política.

2 Entrevistas efectuadas del 6 de agosto de 2013 al 6 de agosto de 2014 en Ecuador.

3 Personas que tienen "habilidades cognitivas" (entrevistados, 2014 y Sumak Yachaypi, Alli Kawsaypipash Yachakuna, 2012).

4 "Un proyecto que se realiza en el análisis del proceso, según el cual la objetividad arraiga en y por la experiencia subjetiva y que debe superar, englobándolo, el momento del objetivismo y fundarlo en una teoría de la exteriorización de la interioridad y de la interiorización de la exterioridad" (Bourdieu, 2001: 12). 
Entonces, ante este nombramiento de embajador, la dirigencia e intelectuales indígenas tildaron a Ulcuango de "traidor" y otorgaron "un voto de rechazo" a la decisión del Ejecutivo por dicho nombramiento. Al respecto, existían dos posturas interesantes. Por un lado, se decía que usar la imagen de un "dirigente histórico" para el cargo de embajador representaba una estrategia de "división y cooptación política" por parte del gobierno. En aquel entonces, Humberto Cholango, presidente de la Conaie, decía:

Ulcuango no cuenta con nuestro aval ni apoyo. Con esta actitud no representa a las luchas dignas e históricas de nuestros héroes y mártires, que prefirieron morir antes que entregarse a intereses ajenos de los pueblos y nacionalidades. ${ }^{5}$

Por otro lado, el gobierno nacional explicaba que la acción fue decidida bajo el "amparo del principio constitucional de la plurinacionalidad".

Ante este panorama, cuestioné: ¿por qué para los actores de la Conaie representar a su país resultaba una pérdida?, ¿por qué Ulcuango era considerado traidor?, ¿qué implicaba la diplomacia en el marco

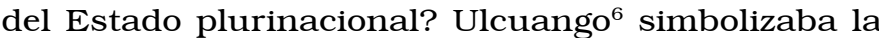
imagen de un intelectual orgánico (en términos gramscianos), debido a su trayectoria política.

A la sazón, entre esas reuniones académicas se rumoraba que "había un nuevo poncho dorado".7 Así, comenzó mi interés por estudiar la construcción discursiva de la figura poncho dorado y la participación de los intelectuales indígenas "etiquetados" como ponchos dorados en el terreno político, articulado con la estrategia política gubernamental y los roles es pecíficos desempeñados por organizaciones ajenas al movimiento indígena en la construcción de estos nuevos tipos complementarios de élites indígenas.

Desde que expuse mi interés recibí fuertes críticas tanto de intelectuales orgánicos (del movimiento indígena), como de intelectuales tradicionales del campo académico. Me aterraban las preguntas de estos últimos: ¿dónde están los ponchos dorados actualmente? o, peor aún, ¿cómo ubicas a un poncho dorado?; de hecho, un año después de que entré al doctorado, encontré a uno de los profesores (que participó en la entrevista de mi postulación) y al saludarme me preguntó: “¿cómo van tus ponchos dorados?”. Durante el trabajo de campo fui hallando hilos clave para recomponer este debate.

Ya en Ecuador, el ejemplo más destacado fue el del economista Pablo Dávalos, que enriqueció la investigación porque criticó firmemente que los conceptos utilizados de élite, autoridad y liderazgo no encajaban para analizar una dinámica dentro del mundo andino, como la conformación de una élite indígena. Aquí me acerqué sin duda a realizar un ejercicio de debate epistemológico sobre los conceptos referidos, desde un pensamiento construido en contradicción directa con el pensamiento occidental: el de las cosmovisiones de los pueblos y nacionalidades indígenas del Abya Yala. ${ }^{8}$ Como paréntesis, esta nueva noción geográfica constituye un producto teórico de los movimientos indígenas por reafirmar su identidad y reapropiarse de su cultura, y se construye como una manera endógena de autodenominación, al representar el conjunto de los pueblos y nacionalidades presentes a nivel continental, desde la Patagonia hasta el Ártico (Tabares, 2012).

Entonces, mediante este ejercicio, mi proyecto reclamaba una reconstitución y reconstrucción teórica epistemológica desde los pueblos ancestrales, pero ¿podría hacer este reclamo hablando sobre el debilitamiento político y organizativo del movimiento indígena; sobre la estratificación social en el mundo indígena?

El académico Dávalos me narró un ejemplo:

Hace 15 años había un burgués indígena con dinero (pariente de Luis Maldonado) que apoyó a la Conaie. Un burgués que tenía su taller, tenía liquidez monetaria y que fue a comprar un automóvil. Iba a comprar un auto a una distribuidora y llevaba el dinero en efectivo, cuando entró a la distribuidora, la persona que atendía le sacó, y le preguntó: “¿qué haces aquí?, tú no puedes entrar”, y él responde: "vengo a comprar un auto, y tengo aquí el dinero". Allí el vendedor desiste, pero el indígena dice: "mejor me voy".

Con este ejemplo, Dávalos me cuestionaba: ¿qué es más fuerte, la relación de clase o la colonialidad

\footnotetext{
5 "Conaie rechaza el nombramiento de Ricardo Ulcuango como embajador de Ecuador en Bolivia”, en Noticias en Línea, 8 de agosto de 2011 <http://noticiasenlinea.com.ec/politica/15577_la-conaie-rechaza-el-nombramiento-de-embajadoren-bolivia-de-ricardo-ulcuango.html> [10 de agosto de 2015].

6 Fue presidente de la Corporación de Organizaciones Indígenas y Campesinas de Cangahua (1988-1990), de la Federación de Organizaciones Indígenas y Campesinas de Pichincha (1991 - 1992), y de la Confederación de Pueblos de la Nacionalidad Kichwa del Ecuador (1996-1999), así como vicepresidente de la Confederación de Nacionalidades Indígenas (1999-2001).

7 Reflexiones de reuniones académicas en la Pontifica Universidad Católica del Ecuador.

8 En lengua del pueblo kuna Abya Yala significa "tierra en plena madurez o tierra de sangre vital” (López, 2004: 4).
} 
del poder?; además, predicó que no existían tales élites indígenas, por lo tanto, "los ponchos dorados era algo especulativo de mi parte”, y su sugerencia iba más por examinar la temática desde la colonialidad del poder.

Por supuesto, durante mi trabajo de campo comprendí que, al utilizar la noción de poncho dorado, operaba esa colonialidad del poder, mediante el racismo como fórmula, pero también el autor otorgaba toda la responsabilidad al racismo. Fue asertivo el planteamiento de Quijano cuando señaló que la colonialidad del poder no ha podido ser erradicada del todo, sin embargo, defendí que no se podía deslindar el carácter clasista del movimiento indígena, y, por lo tanto, era necesario mirar la historia del moderno sistema mundo (Wallerstein, 2013) desde un ángulo de tensiones y contradicciones, pues desde el "indigenismo inconsciente" se ha idealizado la lucha de los pueblos sin ver contradicciones internas, amén de que las categorías clasistas únicamente podían aplicarse para la Revolución Industrial del siglo XIX.

Por otro lado, recibí sugerencias para cambiar el tema del "síndrome del poncho dorado" por "algo más neutral”, "algo menos tendencioso", "menos ofensivo con los pueblos indígenas", "tomar cierta distancia con la categoría nativa", las cuales me provocaban un estado de ansiedad y preocupación para con el movimiento indígena. No obstante, sabía que mi interés por estudiar la estratificación de clase del mundo indígena rompía con la inercia de los atavismos escolares (escolásticos) dentro de la disciplina antropológica.

Una vez comenté a un académico el "acceso" que yo tenía a los consejos ampliados, ${ }^{9}$ por tanto, a las reuniones con los intelectuales y dirigentes indígenas (por lo general, son espacios donde la prensa convencional está prohibida), entonces, me sugirió hacer una antropología del chisme (con toda la información recabada). Quedé más pasmada que indignada; me cuestionaba si la información brindada por los intelectuales quedaba subestimada, ¿no se trataba, entonces, de dejar los "universales antropológicos" para referir las prácticas de los intelectuales indígenas?, ¿qué lugar ocupan las relaciones de poder entre la antropóloga y el conocimiento proporcionado por estos intelectuales? Por supuesto hubo objeciones desde la academia y no faltaron los académicos que pusieron en duda si realmente hacía falta el término poncho dorado, que consideraban peyorativo. Entre las sugerencias recibidas por "conceptos más útiles" estaba el de Charles Hale, neoliberal multiculturalism, y el de burocracia étnica.

Otros académicos tradicionales me dijeron que este trabajo serviría a los "sectores opuestos" al movimiento indígena. La inquietud de quienes debatieron este tema siempre fue "la preocupación de cómo lo que [yo escribiera podría] ser usado políticamente por
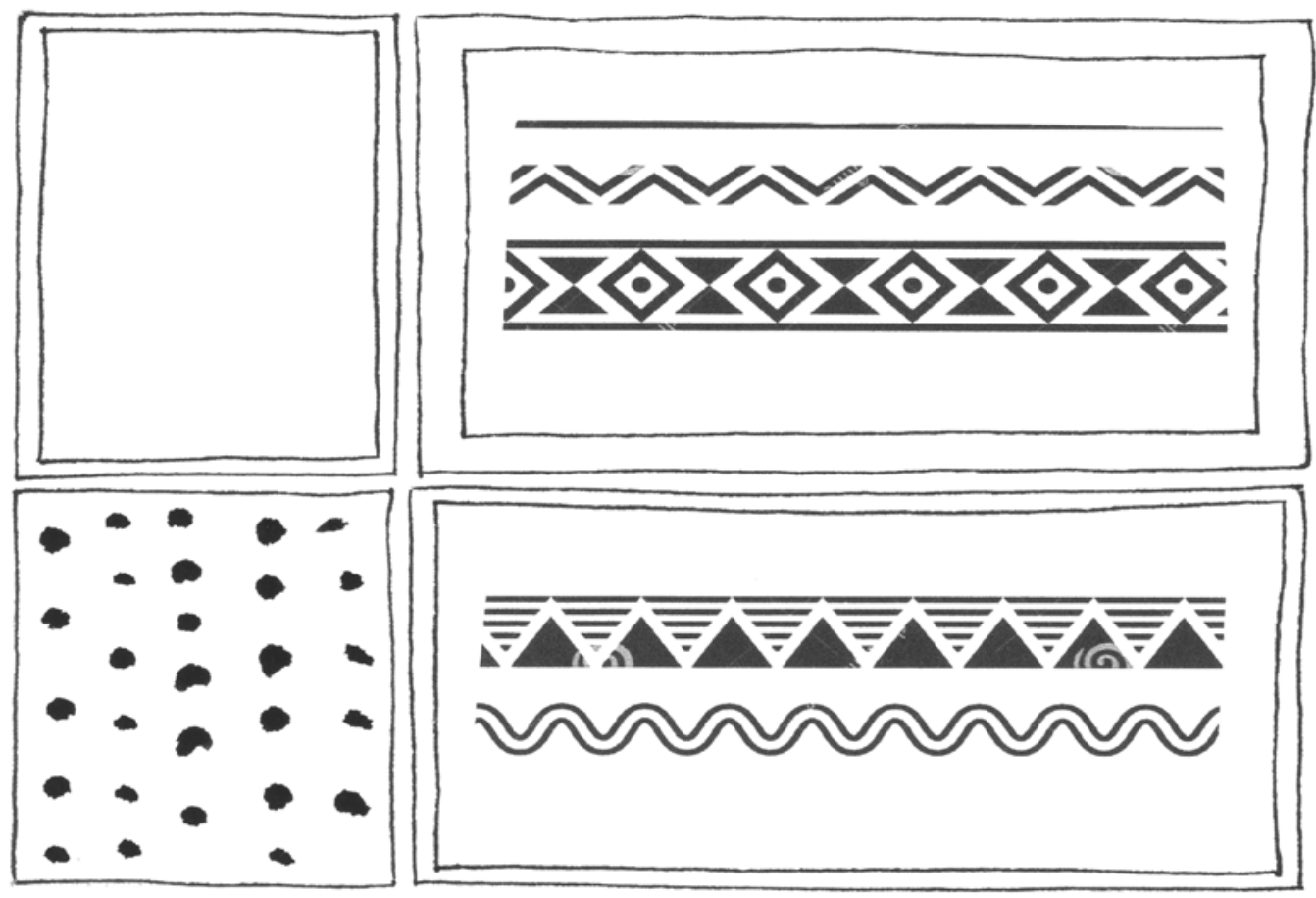

9 Espacios de reflexión colectiva en el que participan los intelectuales, dirigentes y el Consejo de Sabios para tomar decisiones políticas en el movimiento indígena. 
el gobierno para ir contra el movimiento indígena"; inclusive, algunos me relataron sus experiencias sobre cómo el gobierno ecuatoriano - sin citar la fuente- retomaba los argumentos críticos para "agredir" al movimiento. Sin embargo, sostuve que pensar los cambios en este periodo de caos sistémico y de transición de hegemonías (Zibechi, 2008) implicaba abordar la estratificación de clase, sobre todo en un espacio geopolítico que la antropología ha relegado como un campo esencialista y normativo.

La etapa más difícil fue exponer el tema y el uso de los conceptos movilizados acerca de la estratificación social a los intelectuales y dirigentes indígenas. Algunos mencionaban: "la élite es una cosa forzada"; otros decían: "si esa llamada élite indígena existe, no hace parte del movimiento indígena"; también: "esa llamada élite, son indígenas que están intentando y han intentado tener un capital económico"; ${ }^{10}$ inclusive, los intelectuales entrevistados se remontaban a la historia de los otavaleños: "Ellos siempre han tenido un estatus antes del incario, en el incario, en la corona, siempre, pero es un esfuerzo individual y familiar". ${ }^{11}$ En este punto, argumenté que esa élite indígena socioeconómica se acompañaba de una diversificación de capitales generando nuevos tipos de élites indígenas.

Así, algunos intelectuales me invitaron a "tener cuidado" y no "caer en el juego de la academia occidental para hablar de las cabezas emplumadas"; ${ }^{12}$ entonces, después de largas conversaciones, enfatizaban: "debes tener cuidado, porque también eres un poncho dorado que ha tenido acceso a la universidad, a posgrados". De inmediato pensé cómo me presentaría ante las y los intelectuales que me faltaba entrevistar: como antropóloga, como estudiante, como periodista, como poncho dorado de México. Por fortuna, en breve me bautizaron como mashi o compañera.

Los intelectuales orgánicos "más críticos" frente al proceso de debilitamiento del movimiento indígena, que además empleaban en sus respectivos discursos el asunto de la estratificación de clase, me animaban a realizar una evaluación de "esa élite conformada por las mafias internas nuestras que no dejan tener una participación política". ${ }^{13}$
Mientras algunos entrevistados marcaban con claridad que "no entraban o encajaban en esta categoría de élite", ${ }^{14}$ otros intelectuales (que hoy en día no participan en la dinámica política del movimiento indígena) me sugerían analizar el "empobrecimiento de las élites de la Conaie". En este sentido, planteé que mi interés no se centraba en un estudio de la acumulación de un capital económico; esto llevaría a una generalización que, como decía Pacari, "debilitaría sociedades". ${ }^{15}$

Algunos intelectuales indígenas afirmaban: "sí existe esa élite, no tan grande, pero sí tienen un capital cultural, pero ese grupo indígena siempre está coincidiendo con la derecha". ${ }^{16}$ Este punto de vista era clave para la investigación, porque prioricé cómo los intelectuales indígenas han acumulado otros tipos de capitales, no sólo un determinado capital económico, en sus diversas especies.

En relación con el uso del término intelectual orgánico, los intelectuales indígenas explicaban: "para cumplir el reto de construir un verdadero Estado plurinacional hacía falta recuperar a los yachachicuna, ${ }^{17}$ aquellos que tenían el jatun yachay, ${ }^{18}$ esto permitía crear inteligibilidad recíproca entre las experiencias del mundo, tanto las disponibles como las posibles" (Santos, 2010: 46), para comprender el procedimiento de traducción intercultural.

Durante el trabajo de campo me cuestionaban los primeros agentes indígenas: ¿Sabes de dónde surge esta noción de poncho dorado? ¿Por qué usar una categoría para describir lo atrasado, lo peor y donde está de por medio la opresión? ¿No es pretensión de minimización a los pueblos? Con estos interrogantes debía resolver un análisis complejo, pues, en un inicio, no percibí los futuros dilemas, contradicciones e impugnaciones que encontraría en el desarrollo de la investigación.

El primer año del doctorado me cuestioné que, en efecto, poncho dorado representaba una figura discursiva "encarnada" de racismo (sin percibir otro método de análisis posible). De hecho, empecé a argumentar, y con esto modificaba por completo el debate principal de la investigación: "El indígena puede ser élite, pero las estructuras de colonialidad del poder hacen que

\footnotetext{
${ }^{10}$ Entrevistas realizadas entre agosto de 2012 y julio de 2013 en Quito, Ecuador.

${ }^{11}$ Entrevistas, 2014.

12 Entrevistas, 2014.

${ }^{13}$ Entrevistas, 2014.

${ }^{14}$ Entrevistas, 2014.

${ }^{15}$ Entrevista realizada el 14 de octubre de 2013, Quito, Ecuador.

${ }^{16}$ Entrevista realizada el 14 de octubre de 2013, Quito, Ecuador.

17 Dirigentes que están enseñando constantemente.

18 Sabiduría y conocimiento.
} 
no deje de ser indígena". Este cambio se fortaleció cuando me acerqué a los asesores tradicionales ${ }^{19} \mathrm{del}$ movimiento indígena y me invitaron a "no ser parte" de los autores que "atacan" al movimiento "ya de por sí en crisis". ${ }^{20}$

Otro punto que se criticó de manera muy señalada al inicio de este trabajo fue mi planteamiento de que las élites indígenas contribuían a reforzar el debilitamiento político del movimiento indígena, esto es, se objetó el hecho de "mirar a las élites indígenas como perversas”. Sin embargo, en el transcurso percibí que ocurría un proceso de reversión, en el sentido de que los intelectuales coadyuvaban directa o indirectamente al proceso de resistencia al modelo neoextractivista, promovido por el gobierno de la Revolución Ciudadana; entonces también comprobaba que la representación discursiva de poncho dorado "era entrar a competir, a trabajar en las mismas condiciones laborales, es decir, a no tenerles miedo [a la clase política, académica y económica tradicional]". ${ }^{21}$

Hasta después de efectuar otras y cuantificables entrevistas acerca de la conformación histórica de élites indígenas, encontré que los intelectuales censuraban de manera reiterada la figura de poncho dorado. Ante ello, manaba mi interés por buscar cómo se construyó dicha figura, bajo qué parámetros, qué actores participaron en su conformación y por qué se condenaba simbólicamente su uso.

Así que decidí volver a mi análisis esencial para estudiar las contradicciones internas y fisuras políticas del movimiento indígena. Partí del hecho de que mediante la construcción discursiva de poncho dorado el intelectual indígena entraba en escenarios globalizados complejos, lo cual permitía apuntar a una antropología de las élites indígenas.

\section{La noción de poncho dorado}

La noción discursiva de poncho dorado resultó un término emparentado con el racismo; surgió en el marco de la ejecución del Proyecto de Desarrollo de los Pueblos Indígenas y Negros del Ecuador (Prodepine) en $1998,{ }^{22}$ y se vinculaba directamente con el salario que ganaban los técnicos indígenas que laboraban en él. En efecto, los entrevistados relacionaban siempre esta expresión con un tipo de capital económico.

Como resultado, usar esta representación fue útil para explicar el espacio social donde los agentes estaban distribuidos, esto es, ayudó a debatir cómo los intelectuales indígenas estaban "dotados de disposiciones similares", que los llevaba a desarrollar "prácticas similares" en la lucha histórica de la construcción del Estado plurinacional.

También fue útil porque apuntó justo al centro de la controversia y abrió varias cuestiones ocultas bajo lo "políticamente correcto" en torno a las categorías racismo, etnia y clase: ¿pueden los indígenas ser élite? Con esta noción se rompieron los roles que histórica y culturalmente correspondían al indígena, y de este modo, la estigmatización del ser indígena.

Entre los componentes epistemológicos de la estructura de la cosmovisión kichwa andina existe el concepto de yachak, el cual describe a las personas que "están informando sobre algo", que "dominan determinadas letras o arte", ${ }^{23}$ y que tienen el yachay, es decir, el saber, en un sentido de "habilidades cognitivas", y poseen un reconocimiento institucional de un capital cultural particular.

Entonces, retomar la figura de poncho dorado sirvió para analizar que una de sus representaciones constituía la cúspide de la dirección política en la cultura de la clase blanco-mestiza. Era una figura amonestada, debido a que el sujeto indígena irrumpía y, sobre todo, se empezaba a movilizar en espacios tradicionalmente occidentales, o asumía roles que de manera sistemática "no le correspondían", por lo general "sancionados" en el mundo indígena, pues implicaba una especie de "traición" y, por ende, el sujeto indígena recibía el castigo simbólico: la etiqueta de poncho dorado.

Otro aspecto analítico fue que poncho dorado encarnaba un concepto investido de una tácita "ambición de autoridad", en el que recaía todo el significado de las "prácticas racistas" de percibir al sujeto indígena. Conllevaba, en este sentido, la "perpetuación de la relación de dominación" entre el indígena y las clases oligarcas que participaron en el Prodepine.

Respecto a la noción orgánico, usé la propuesta de Gramsci (1967) para explicar la creación de relaciones orgánicas dentro del movimiento indígena en

\footnotetext{
${ }^{19}$ Así se autonombran determinados académicos que participan en las movilizaciones de la Conaie y asisten a los consejos ampliados.

${ }^{20}$ Entrevistas, 2014

${ }^{21}$ Nina Pacari, entrevista realizada el 14 de octubre de 2013, Ecuador.

${ }^{22}$ El Prodepine se creó en 1997 y se puso en marcha a partir de 1998. Incluye a 19 de las 22 provincias del Ecuador, a 108 de los 213 cantones y a 434 de las 788 parroquias rurales del país.

${ }^{23}$ Entrevistados, 2014 y Sumak Yachaypi, Alli Kawsaypipash Yachakuna, 2012.
} 
el transcurso de una lucha por un nuevo modelo de Estado. Por consecuencia, fue interesante visualizar cómo aconteció, según los testimonios, el proceso del intelectual orgánico a la figura discursiva de poncho dorado.

En la actualidad, de acuerdo con los intelectuales indígenas, hablar de poncho dorado constituye una descalificación destinada a la dirigencia indígena de oposición al gobierno de la Revolución Ciudadana. Sé que las lecturas políticas que resultarían de este estudio podrían tergiversarse y ser utilizadas en contra del movimiento indígena, sobre todo en la coyuntura política de persecución que atraviesa el movimiento. No obstante, la principal virtud del estudio de la élite indígena radica en revelar los mecanismos sociales de dominación, movilizados por esta clase social, con el fin de asentar la autoridad simbólica que legitima su poder de decisión política en los diversos ámbitos de la actividad social. En esta línea, pretendo aportar a la reflexión y así romper con la discreción que envuelve las estructuras del poder. Como dice Pacari (2007: 88), la autocrítica reflexiva no será para encontrar "culpables o responsables", sino para ubicar con madurez los equívocos y corregirlos en dirección del proyecto político que avizoran los pueblos indígenas.

\section{Origen del problema}

Para investigar y contextualizar los orígenes de las élites indígenas en Ecuador, fue importante retomar un breve análisis sobre las transformaciones sufridas por la sociedad ecuatoriana, en virtud de que respondían a procesos de transformación del país (Zibechi, 2008). Esto me remitió a la democratización política -ocurrida en la transición democrática de 1979 y en la imposición del neoliberalismo-, proceso que llevó al movimiento indígena a abandonar toda pretensión sobre un cambio social radical, para orientar su acción hacia un cambio de régimen.

Este giro de estrategia quedó de manifiesto en los derrocamientos sucesivos de los gobiernos de Abdala Bucaram y Jamil Mahuad, pues las demandas sociales se subordinaron a las metas de coyuntura política. Las negociaciones entre las élites tradicionales y el Movimiento de Unidad Plurinacional Pachakutik-Nuevo País (MUPP-NP) tendieron a reemplazar las movilizaciones sociales (ejemplo de la alianza electoral con la candidatura de Lucio Gutiérrez en 2003).

Asimismo, el antagonismo entre ciudadanía y exclusión orientó las reivindicaciones del movimiento indígena tanto hacia la defensa y conquista de nuevos derechos colectivos, como hacia la superación de nuevas formas de pobreza. Además, la redefinición del modelo nacional de desarrollo económico, ante la llamada década perdida de los ochenta, condujo al movimiento a la formulación de proyectos políticos alternativos, con el propósito de contrarrestar la debilidad creciente del espacio público.

Por último, la necesidad de repensar la modernidad atravesó por la propuesta de un modelo cultural distinto del paradigma occidental dominante, con base en la promoción de la diversidad, las identidades y las culturas plurales (Zibechi, 2008).

Ante este escenario de discriminación y exclusión del Estado ecuatoriano, el movimiento indígena planteó la creación de un proyecto político nacional incluyente: el Estado plurinacional, que, en términos de Luis Macas (2005: 38), significó "una reformulación de la democracia. No solamente representativa, sino una democracia participativa, comunitaria, basada en el diálogo, en el consenso, en la revocatoria”.

Entonces, se empezó a vislumbrar el paradigma del sumak kawsay, que cuestionó la milenaria relación de dominio entre la naturaleza y los hombres, debido a que sólo complacía la explotación de los recursos no renovables sin mirar los efectos catastróficos; se discutía, pues, la "interrelación y reciprocidad" entre cosmos, hombre, naturaleza y sociedad. ${ }^{24}$ Desde este panorama, consideré al movimiento indígena como la expresión de sobrevivencia, descomposición y reconstrucción del tejido social de los pueblos, en un contexto de globalización.

\section{Élites indígenas}

Aplicar la categoría de élite a un campo social considerado como subversivo y, en apariencia, contradictorio con esta misma categoría -en este caso el mundo indígena-, puede sonar discordante. Aquí argumento la pertinencia de este concepto no porque represente una categoría impuesta desde afuera, por los no indígenas sobre los indígenas, o por los antropólogos sobre los informantes, sino porque es una categoría que ya se encuentra en los discursos de los propios dirigentes e intelectuales indígenas, y se construye en relación directa con la realidad política, social y económica de grupos y sectores, internos a los pueblos y nacionalidades, hoy cada vez más visibles y potentes.

Cuando hablo de una nueva clase social en el Ecuador contemporáneo me refiero a una clase conformada

${ }^{24}$ Proyecto político de la Conaie, 1994. 
por los yachaks (intelectuales que poseen grados académicos), que participan en la propuesta política de la Conaie para la refundación del Estado, así como en el Prodepine, y que comparten un espacio asimétrico de producción y distribución del capital. Los intelectuales indígenas se desenvuelven en un campo social, particularmente, en los campos político y académico (Bourdieu, 2011).

Los intelectuales se identifican con sus respectivos pueblos o nacionalidades indígenas, explican que viven de acuerdo con su cosmovisión kichwa andina y se movilizan en un campo de poder donde prevalecen "las relaciones de fuerza entre las diferentes especies de capital" e incorporan un habitus en función de su posición social (Bourdieu, 2001: 20); a esta clase social la denomino élite indígena ( $\sin$ perder de vista las distintas fracciones de clase que vienen dadas por los capitales que poseen y por la trayectoria que eligen).

En términos de Bourdieu, una clase social se define por "la estructura de las relaciones entre todas las propiedades pertinentes" (2001: 20). Aquí subrayo que hablo de clase social porque tomo por separado la población indígena, como una sociedad en sí, de sectores mestizos existentes. Esto es, hay una élite mayoritariamente académica y una mayoritariamente política, porque los sectores sociales correspondientes con estos tipos vienen acumulando en proporciones desiguales diferentes tipos de capital.

Antonio Gramsci distingue entre intelectuales tradicionales y orgánicos; los últimos surgen sobre el "terreno a exigencias de una función necesaria en el campo de la producción económica” (1967: 22).
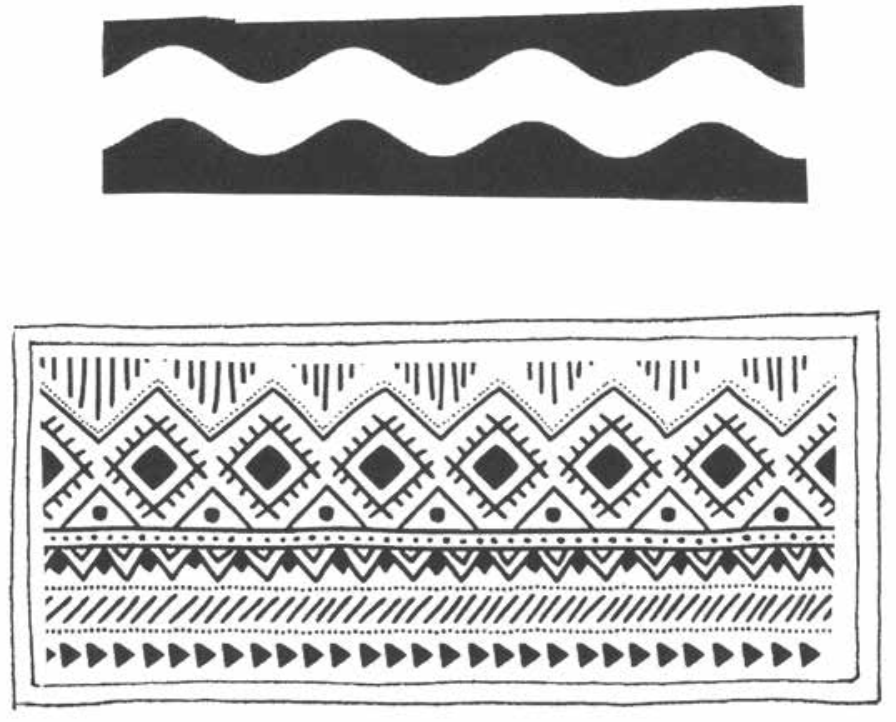

${ }^{25}$ Entrevistas, 2014.
El tipo de intelectual que describe el autor está "ligado orgánicamente al desarrollo de la organización política de la clase obrera”, por ende, se forja en el movimiento campesino y refuerza su "organicidad impulsando a los grupos emergentes de la clase trabajadora" (Gramsci, 1967: 22). En el sentido gramsciano, los intelectuales orgánicos nacen del movimiento campesino en el país andino. Aquí, la dinámica del movimiento claramente es clasista, en contra del terrateniente, el hacendado y el latifundista, de ahí que demande acceso a la tierra, a los servicios básicos, a la reforma agraria y a la defensa del idioma nativo; para conseguir sus fines, se constituyeron en la Federación Ecuatoriana de Indios (FEI), y más tarde en la Conaie. Siguiendo los apuntes de Gramsci, este nuevo tipo de intelectual dirigente "nada tiene que ver con ciertas figuras inveteradas de caudillos políticos que se confiaban preferentemente en la oratoria y en la emoción" (Gramsci, 1967: 26).

Los intelectuales orgánicos colaboran en la propuesta política de la Conaie sobre las bases doctrinales de la plurinacionalidad y la interculturalidad. Empero, las trayectorias políticas de los intelectuales orgánicos les abren espacio para participar ahora como intelectuales “tradicionales”. Gramsci explica que estos últimos trabajan con el sector hegemónico.

En este proceso, algunos intelectuales se alejan de la lucha del movimiento indígena, acumulan capital cultural a través de títulos académicos -que representan un reconocimiento institucional de este capital-y encuentran un espacio privilegiado de expresión en el campo académico. El trabajo de estos intelectuales tiene legitimidad, aunque no estén participando activamente en el movimiento. No obstante, son cuestionados a la hora de manifestar un discurso en nombre de todas las nacionalidades.

En este estudio, pues, se visualiza una participación en el campo académico por parte de los intelectuales indígenas, quienes se posicionan para abordar debates que habían sido monopolizados por los cientistas tradicionales al hablar de los pueblos indígenas. En cambio, otros intelectuales relatan que no han perdido la conexión con la gente de las comunidades, y desde espacios académicos mantienen un vínculo con chamanes. ${ }^{25}$

Asimismo, distintos agentes indígenas han acumulado una especie de capital político, como es el caso de los fundadores, dirigentes y asambleístas del MUPP$\mathrm{NP}$; también han participado en conferencias nacionales e internacionales y obtenido diversos premios (por ejemplo, el Premio Bartolomé de las Casas). Además, han sido becarios de organismos internacionales. Sus 
prácticas les han permitido la acumulación de un capital, "más que en forma de materia, en forma incorporada" (Bourdieu, 2001: 31).

Cabe resaltar que la élite indígena, al margen de sus campos de acción, tiene un común denominador: la identidad étnica. Es decir, quienes la conforman se posicionan como miembros de un colectivo histórico con base en una política identitaria ${ }^{26}$ y están dotados de un discurso étnico cultural. Los discursos empleados en los campos académico, político e incluso económico tienen como base un discurso indígena, que se encuentra en la práctica de los intelectuales y representa el producto de un proceso estructural de lucha de los pueblos indígenas.

\section{Reflexiones finales: dilemas y rupturas entre yachak y la figura del poncho dorado}

Para concluir, señalaré determinados elementos descriptivos acerca de los dilemas y rupturas que existen entre los yachak y la figura discursiva de poncho dorado. Durante el trabajo de campo, seleccioné las trayectorias políticas ${ }^{27}$ de tres intelectuales indígenas: Tituaña, Kowii y Tibán, los más nombrados como miembros de una élite y etiquetados como ponchos dorados. Pero merece la pena aclarar que no debe leerse élite y poncho dorado como sinónimos.

Entonces, ¿por qué los intelectuales mencionados reciben esta etiqueta como sanción simbólica? De acuerdo con los testimonios, una de las columnas discursivas de la figura de poncho dorado es que se ha construido mediante características occidentales, en consecuencia, representa una figura de la estructura social de la clase blanco-mestiza y, por consecuencia, se encuentra fuera de la cúspide de los yachachicunas (dirigentes que están enseñando constantemente).

En la trayectoria política de Kowii, se encuentra su calidad de élite tan sólo como intelectual. No es casual que el intelectual priorice temáticas culturales respecto del pueblo quichua Otavalo, sobre todo por la fuerza política del movimiento cultural que se constituyó durante la década de los setenta en ese lugar a fin de fortalecer la identidad cultural.
Para los intelectuales movilizados dentro del movimiento indígena, la competencia cultural o los bienes culturales de los intelectuales movilizados en el campo académico sólo encuentran sentido cuando la capacidad de poder de estos conocimientos sea parte de la dinámica del movimiento, y cuestionan: ¿A quién beneficia esta forma de pensar por más indio que sea dentro de la academia? ${ }^{28}$ Por lo general argumentan que "sirve a la misma producción de conocimiento occidental, no de los pueblos indígenas", ${ }^{29}$ y ponen en duda a quienes ensamblan un discurso en nombre de todos los pueblos.

En cuanto a la trayectoria política de Kowii, es posible observar que su "separación" del movimiento indígena se debe a las disputas que genera su posición respecto de la educación intercultural bilingüe. Así, el agente mantiene relaciones simbólicas con las bases militantes y no con la dirigencia del movimiento.

Por su parte, Tituaña y Tibán son representantes de la élite del campo político. Tibán, exasambleísta por el Movimiento Pachakutik, moviliza su capital cultural y académico en pos del capital político. En cuanto a Tituaña, su capital económico le permite movilizarse en otros campos sociales, como el político y el académico.

Tituaña se moviliza fuera $^{30}$ del movimiento indígena, y la crítica más reiterada que recibe es que lo hace directamente con sectores de centroderecha. A partir de sus vínculos con este sector político y por "pactar con la derecha", el exalcalde de Cotacachi recibe un "castigo" simbólico: la expulsión del Movimiento Pachakutik. ${ }^{31}$

Además, Tituaña también es cuestionado porque la adquisición de poder o de propiedades objetivadas e incorporadas ha sido en función de "méritos individuales olvidándose del proceso organizativo de lucha", es decir, porque su trabajo se conjuga en el ámbito individual y familiar y no en el colectivo. Aquí, sin duda, el predominio de lo comunitario rechaza una visión basada en la condición de la individualidad. La noción de las élites encuentra vigencia en el alli kawsay, que significa (además de armonía) conformidad, vivir mejor y prosperidad económica (Macas, 2005). Entonces, otra de las razones por la que los agentes son etiquetados y señalados bajo la figura

\footnotetext{
${ }^{26}$ Retomé el término como lo proponen los intelectuales indígenas. También este término se encuentra en la propuesta de Rappaport.

${ }^{27}$ Debido al espacio, las historias de vida se resumen.

${ }^{28}$ Entrevistas realizadas del 6 de agosto de 2013 al 6 de agosto de 2014 en Ecuador.

${ }^{29}$ Entrevistas, 2014.

${ }^{30}$ Es decir, no participa en la toma de decisiones políticas del movimiento indígena.

${ }^{31}$ Entrevistas, 2014.
} 
discursiva de poncho dorado es que esa "prosperidad" no se sostiene en el ámbito comunitario.

En cambio, a Tibán no se le objeta, por ejemplo, la acumulación de un determinado capital económico, debido a que cumple el mandato comunitario con "deberes", con la minka o maki maki (trabajo obligatorio). Tibán se vincula con su comunidad mediante participaciones sociales; para ilustrar, "ha tenido muchos ahijados", ${ }^{32}$ y se rige, en este sentido, bajo el principio del ayni (solidaridad de la familia y la vecindad). En síntesis, la perspectiva del trabajo (propia de la cosmovisión de las nacionalidades indígenas) tiende a reproducir la vida comunitaria en forma de redes de autoorganización, y debe prevalecer el maki purarina (darse la mano) y la solidaridad con los miembros de la comunidad (Kowii, 2014: 165).

Para los intelectuales movilizados dentro ${ }^{33} \mathrm{del} \mathrm{mo-}$ vimiento indígena, Tibán representa una mujer preparada con formación académica y se valora el hecho de que, con su capital social y los aspectos simbólicos que moviliza, "no se va por otro lado", o sea, la perciben con un carácter "colectivista que ayuda al movimiento", pero le cuestionan "el descontrol de las reacciones compulsivas" que debe tener como "virtud" un yachak (intelectual).

En este sentido, la etiqueta discursiva de poncho dorado asignada a Tibán proviene principalmente de la oposición, de intelectuales movilizados en el campo académico y político sin participación activa en el movimiento indígena, a diferencia de Kowii y Tituaña, quienes son etiquetados como ponchos dorados por algunos intelectuales activos dentro del movimiento $y$, con frecuencia, por las bases comunitarias. De hecho, es interesante advertir que las élites indígenas son impugnadas por sus propias poblaciones, lo que representa un reclamo profundo a las clases, a las formas de hacer política, así como a sus posiciones en el espectro político.

En cuanto a la figura discursiva de poncho dorado, Tibán y Kowii le atribuyen una connotación racista, mientras que Tituaña es crítico hacia el término, no obstante él mismo explica "ser señalado como poncho dorado" y, dice: "soy pendejo porque no hice fortuna, negocios; para unos soy pendejo, para otros soy una élite indígena"; reconoce ese racismo que mencionan los agentes, pero defiende la existencia de clases sociales en el interior del movimiento, no como sectores dominantes, sino como intelectuales movilizados en diversos espacios sociales en contextos globalizados.
Respecto al debate de la configuración de las élites, Kowii define a esta clase en relación con los medios de producción, mientras Tituaña subraya la estratificación social, debido a las condiciones históricas que atraviesan los pueblos indígenas, y Tibán vincula el tema directamente con esfuerzos individuales, "sin perder de vista las responsabilidades con el sistema comunitario". ${ }^{34}$

En síntesis, el ascenso social de las élites se cuestiona porque se ha realizado a través de liderazgos individuales y jerárquicos (uso predominante en la vieja izquierda), provocando que pierda sentido la propuesta de una dirección colectiva y horizontal, característica del movimiento indígena; por tal motivo existe una sanción simbólica para los agentes que se "individualizan", y que son parte de las "crisis de las formas antiguas de liderazgos".

Otra crítica que se hace al ascenso social de las élites es que éstas se acercan más a la perspectiva de liderazgo del mundo occidental (es decir, a la figura discursiva de poncho dorado), y se opaca la perspectiva del yachachicuna, que necesariamente debe cumplir principios básicos, virtudes y funciones en tres ámbitos: individual, familiar y colectivo, bajo los valores esenciales: ama killa, "no a la pereza", ama llulla, "no a la mentira", ama shua, "no al robo", que en conjunto se encuentran en el pensamiento Llankayka kushikuypa shunkumi kan, "El trabajo es el corazón de la felicidad" (Kowii, 2014). Surge entonces la crítica hacia los intelectuales indígenas que se desempeñan mediante los parámetros occidentales y no mediante los del mundo andino.

Desde este panorama, se cuestiona la tarea principal del yachak, debido a la falta del pakta kausay (equilibrio) y la alli kawsay (armonía), que no le permiten cumplir con el mandato comunitario: la minka (trabajo obligatorio). Como reflexión final, es útil identificar que los intelectuales pueden ser una combinación de ambos pensamientos, debido a que se movilizan simultáneamente según los conceptos kichwas y los conceptos occidentales.

Otro resultado de la investigación fue identificar que las élites indígenas "más aceptadas" simbólicamente son las que se movilizan y participan en el interior del movimiento indígena, como el caso de representantes de las élites políticas; en cambio, representantes de las élites movilizadas en el campo académico no adquieren la misma dimensión en la toma de decisiones políticas que emprende el movimiento.

\footnotetext{
${ }^{32}$ Entrevistas realizadas del 6 de agosto de 2013 al 6 de agosto de 2014 en Ecuador.

${ }^{33}$ Partícipes en toma de decisiones políticas.

${ }^{34}$ Reflexiones en un consejo ampliado convocado por la Ecuador Runacunapac Riccharimui (Ecuarunari).
} 
Estas últimas élites sostienen la urgencia de diferenciar entre la izquierda y la derecha ecuatoriana, debido a las coaliciones políticas (en el marco de las elecciones presidenciales de 2017) de las élites indígenas políticas y sus vínculos con las élites tradicionales de derecha (lo cual no significa las élites indígenas se encuentren en un estado de "guerra" entre ellas). En relación con las alianzas políticas entre las élites indígenas y las tradicionales, se generan rupturas y disputas dentro del movimiento indígena. Los tres intelectuales mencionados apuntan y reconocen que prevalece un resquebrajamiento en el interior del movimiento, en consecuencia, visualizan la existencia de una "crisis organizativa", tanto en la Conaie como en el MUPP-NP.

Con las élites indígenas se observan diferentes especies de capital y modos de circulación correspondientes, que les permiten negociar con las élites tradicionales; tales negociaciones no por fuerza tienen que ver con recursos estrictamente económicos, sino que las relaciones establecidas para realizar coaliciones políticas están en función de las distintas especies de capitales de dichas élites.

Por ejemplo, participar en coaliciones políticas hace que las élites indígenas se posicionen conscientes en las negociaciones para confrontar el proyecto político de Alianza País. En la actualidad, las élites conformadas en la época neoliberal ingresan a otro escenario: a la época posneoliberal de la Revolución Ciudadana. Es decir, las élites indígenas que priorizan coaliciones (sin importar sus posiciones políticas) mantienen un rol activo en relación con las élites tradicionales, debido a que resultan, según los entrevistados, "necesarias para el emergente debate respecto la plurinacionalidad". 35

En suma, las élites indígenas están conscientes de las estrategias y "riesgos calculados" del respectivo ejercicio en el campo político. Lo que está en juego, como dicen Wallerstein y Balibar (1991: 24), es el aspecto político de la lucha de clases; al mismo tiempo, recurren a un discurso indígena para argumentar sus vínculos con la derecha, la centroderecha y la centroizquierda.

Las élites comparten similares factores condicionantes y constituyen la identidad como elemento político. Esto no significa que como clase social no se encuentren fragmentadas; las élites conllevan un pro- ceso de conflictos internos, lo que Althusser denomina sobredeterminación del antagonismo, debido a que no hay un tipo ideal de élite indígena.

En este sentido, las críticas al ascenso social de los agentes indígenas responden sobre todo a los siguientes puntos. En primer lugar, al distanciamiento de los agentes indígenas respecto de sus bases comunitarias, debido a la búsqueda de prebendas institucionales por parte de los primeros, desvirtuando las razones de la lucha histórica emprendida por las segundas. En segundo lugar, las élites también son criticadas en el campo político, porque han "servido" a un Estado que no ha respondido a las demandas de las nacionalidades indígenas, es decir, son cuestionadas porque participan en un Estado posneoliberal, ${ }^{36}$ que se sostiene en un proyecto neoextractivista, y que enarbola un modelo de desarrollo denominado "nueva era petrolera" (con la paradoja de la minería responsable).

Actualmente, el conflicto radica en que este proyecto del Estado posneoliberal entiende el proyecto político de la Conaie (con base en la interculturalidad y la plurinacionalidad) como una simplificada y reducida versión folclórica de los símbolos de los pueblos y nacionalidades indígenas, y no como un verdadero cambio paradigmático para el quehacer político del buen vivir. Por consecuencia, en el proyecto posneoliberal que ha priorizado el gobierno de Rafael Correa, esto se traduce en una propuesta discursiva de cambio de matriz productiva, conforme la cual las temáticas relacionadas con las nacionalidades indígenas quedan relegadas, y prevalecen sectores estratégicos como refinería, petroquímica, metalurgia y siderúrgica.

La interpretación institucional respecto del paradigma del buen vivir refuerza los dilemas y se vigoriza la complicada relación entre el movimiento indígena y el gobierno. Entonces, el debate se encuentra vigente en los dilemas entre dos proyectos políticos. Mientras que el proyecto posneoliberal enarbola un modelo neoextractivista, que pretende "transformar el patrón de especialización de la economía con el fin de lograr una inserción estratégica y soberana en el mundo", ${ }^{37}$ el proyecto planteado por la Conaie reclama la gestión responsable de los bienes naturales y exige una alternativa a la economía minera. En esta dirección, las críticas al ascenso de los intelectuales es que se ubiquen en una transición de lo orgánico

\footnotetext{
${ }^{35}$ Diversas entrevistas realizadas del 6 de agosto de 2013 al 6 de agosto de 2014 .

${ }^{36}$ En este artículo, se simpatiza con Dávalos y Zibechi cuando plantean que el posneoliberalismo es una continuidad del modelo neoliberal, y no una ruptura con el neoliberalismo clásico, y lo definen como un "proceso complejo en el que continúa, se profundiza, se consolida y se extiende la violencia neoliberal” (Dávalos, 2014: 52 y Zibechi, 2008).

37 Empresa Nacional Minera <www.enamiep.gob.ec>.
} 
a lo tradicional y no al revés, como plantea Gramsci: "los intelectuales tradicionales pueden ser absorbidos dentro del cuadro de los intelectuales orgánicos” (cit. en Rappaport, 2007: 52). Las objeciones a este ascenso social se deben a que se ha logrado con el "enemigo político".

El último punto es que las élites indígenas aparecen posicionadas (definidas relacionalmente), y se revela que, en la medida que se conforman, se encuentran inmersas en las posiciones políticas anteriormente negadas de manera sistemática al sujeto indígena.

Así pues, la construcción de las élites indígenas es producto de un largo proceso histórico, y éstas se definen por posiciones privilegiadas, ya no en las relaciones de producción, sino en la dirección política de las sociedades (ya que ahora ocupan puestos), y se cohesionan como grupos con identidad de clase, es decir, como clase social dominante para sí misma.

\section{Fuentes}

Bourdieu, Pierre

2001 Poder, derecho y clases sociales, $2^{\mathrm{a}}$ ed., Desclée de Brouwer, Bilbao.

Bourdieu, Pierre

2011 Las estrategias de la reproducción social, Siglo XXI Editores, Buenos Aires.

DÁvalos, PaBlo

2014 Alianza PAIS o la reinvención del poder. Siete ensayos sobre el posneoliberalismo en el Ecuador, Ediciones Desde Abajo, Bogotá.

Gramsci, Antonio

1967 La formación de los intelectuales, Grijalbo, México.

Kowit, Ariruma

2014 "El Sumak Kawsay", en Antonio Luis Hidalgo-
Capitán, Alejandro Guillén García y Nancy Deleg Guazha (eds.), Antología del pensamiento indigenista ecuatoriano sobre sumak kawsay, Proyecto de Cooperación Interuniversitaria para el Fortalecimiento Institucional de la Universidad de Cuenca en Materia de Movilidad Humana y Buen Vivir, Huelva y Cuenca, pp. 159- 168.

López Hernández, Miguel Ángel

2004 Encuentros en los senderos de Abya Yala, Abya Yala, Quito.

MacAs, Luis

2005 "La necesidad política de una reconstrucción epistémica de los saberes ancestrales", en Pueblos indígenas, Estado y democracia, Consejo Latinoamericano de Ciencias Sociales, Buenos Aires, pp. 35-43.

PACARI, NINA

2007 Todo puede ocurrir, Universidad Nacional Autónoma de México, México.

RAPPAPORT, JOANNE

2008 Utopías interculturales. Intelectuales públicos, experimentos con la cultura y pluralismo étnico en Colombia, Universidad del Rosario, Bogotá.

SAntos, BoAventura de Sousa

2010 Refundación del Estado en América Latina: perspectivas desde una epistemología del Sur. Siglo xxi Editores/Universidad de los Andes, Bogotá.

Tabares, Gema

2012 Periodismo indígena. La minga de pensamientos y acciones sobre la comunicación indígena, Facultad Latinoamericana de Ciencias Sociales, Quito.

WALLERSTEIN, IMMANUEL

2013 El capitalismo histórico, Siglo xxi Editores, México.

WALLERSTEIN, IMMANUEL

Y ETIENNE BALIBAR

1991 Raza, nación y clase, IEPALA Textos, Madrid.

ZIBECHI, RAúL

2008 Autonomías y emancipaciones: América Latina en movimiento, Bajo Tierra Ediciones, México. 